\title{
Impact of Magnification Views on the Characterization of Microcalcifications in Digital Mammography
}

\section{Einfluss der Vergrößerungsaufnahme auf die Charakterisierung von Mikroverkalkungen in der digitalen Mammografie}

Authors

Affiliations
E. M. Fallenberg' ${ }^{1}$ L. Dimitrijevic ${ }^{2}$, F. Diekmann 3 , S. Diekmann ${ }^{4}$, U. Kettritz ${ }^{5}$, A. Poellinger ${ }^{1}$, U. Bick ${ }^{6}$, K. J. Winzer ${ }^{7}$, F. Engelken ${ }^{6}$, D. M. Renz ${ }^{1}$

Affiliation addresses are listed at the end of the article.

\author{
Key words \\ - breast \\ - breast radiography \\ - screening \\ - mammography \\ microcalcifications
}

\section{received 25.1.2013}

accepted $\quad 7.8 .2013$

\section{Bibliography \\ Dol http://dx.doi.org/ \\ 10.1055/s-0033-1350572 \\ Published online: 2.9.2013 \\ Fortschr Röntgenstr 2014; 186: \\ 274-280 @ Georg Thieme \\ Verlag KG Stuttgart · New York . ISSN 1438-9029}

\section{Correspondence Dr. Eva Maria Fallenberg Institut für Radiologie, Charité Universitätsmedizin Berllin Charitéplatz 1 \\ 10115 Berlin Germany \\ Tel.: 0 30/450/527082 \\ Fax: 030/4 50/52 7911 \\ eva.fallenberg@charite.de}

\section{Zusammenfassung \\ $\nabla$}

Ziel: Evaluation des Nutzen geometrischer Vergrößerungsaufnahmen für die Charakterisierung von Mikroverkalkungen in der digitalen Mammografie.

Material und Methode: Nach positivem Ethikvotum selektierten wir retrospektiv anhand der Befundberichte 100 Patienten mit suspekten Mikroverkalkungen (35 maligne, 65 benigne), die innerhalb von 3 Monaten eine Standardmammografie (MG) und eine Vergrößerungsaufnahme (MAG) in der gleichen Ebene bekommen haben. Alle Aufnahmen wurden an einem VolldetektorSystem (Senografe 2000 D, GE Healthcare, Chalfont St. Giles, UK) erstellt. Die Bilder wurden von 6 unabhängigen Radiologen analysiert. Die Malignitätswahrscheinlichkeit der MG alleine und dann folgend der MG plus MAG wurde bestimmt. Die Ergebnisse wurden mittels ROC-Analyse verglichen. Zusätzlich wurde die Sichtbarkeit der Verkalkungen beurteilt.

Ergebnisse: Die Area under curve (AUC) betrug für alle Reader kombiniert 0,664 $\pm 0,052$ für $M G$ und $0,813 \pm 0,042$ für $M G+M A G$, einer signifikante Verbesserung von $0,148 \pm 0,120$ entsprechend. Jeder Reader erreichte eine höhere AUC für MG + MAG als für MG, diese Verbesserung war bei vier Readern signifikant. In 76,34\% der Fälle zeigte MG + MAG eine bessere Sichtbarkeit der Kalzifikationen. Bei 33\% waren gering mehr, bei 39\% deutlich mehr Verkalkungen abgrenzbar.

Schlussfolgerung: Auch bei Einsatz der digitalen Mammografie mit den Möglichkeiten der elektronischen Vergrößerung bei Bildschirm-Befundung kann nicht auf geometrische Vergrößerungsaufnahmen verzichtet werden, da diese für die korrekte Klassifizierung und Ausdehnungsbeurteilung von Mikroverkalkungen weiterhin wichtig sind.

\section{Abstract \\ $\nabla$}

Purpose: To evaluate the additional benefit of true geometric (air-gap) magnification views for the characterization of microcalcifications in digital mammography.

Materials and Methods: After ethical approval, we retrospectively reviewed patient records to identify 100 patients with suspicious microcalcifications (35 malignant, 65 benign) who had a standard digital mammography and an additional digital magnification view in the same projection within three months. All images were obtained using an amorphous silicon-based full-field digital system (Senographe 2000 D, GE Healthcare, Chalfont St. Giles, UK). Images were independently analyzed by six board-certified radiologists. The probability of malignancy was estimated using first standard contact mammography alone (MG) and then mammography in combination with the magnification view (MG+MAG) using a modified Breast Imaging Reporting and Data System (BIRADS) classification system and a percentage scale. Results were compared using receiver operating characteristic (ROC) analysis. In addition, readers assessed the subjective visibility of the calcifications.

Results: For all six readers combined, the area under the curve (AUC) was $0.664 \pm 0.052$ for MG and $0.813 \pm 0.042$ for MG + MAG, resulting in a statistically significant improvement of $0.148 \pm 0.120$. Each reader had a higher AUC for MG + MAG than MG, with the improvement being statistically significant in four of the six readers. In $76.34 \%$ of the cases, MG + MAG resulted in better visibility of calcifications compared with mammography alone. In $33 \%$ slightly more and in $39 \%$ significantly more calcifications were found.

Conclusion: Even in digital mammography with the option of using electronic magnification (zoom) at the viewing workstation, true geometric (air-gap) magnification views remain impor- 
tant for the visibility and correct classification of microcalcifications and for the assessment of their extent.

Citation Format:

- Fallenberg EM, Dimitrijevic L, Diekmann F etal. Impact of Magnification Views on the Characterization of Microcalcifications in Digital Mammography. Fortschr Röntgenstr 2014; 186: $274-280$

\section{Introduction}

$\nabla$

Microcalcifications are, along with the mass-like appearance of breast lesions, the most important sign of malignancy and are the key finding to detect in situ and early invasive cancers in screening mammography [1]. Although some microcalcifications may also be seen with modern high-resolution ultrasound [2], many, especially smaller, areas of tiny microcalcifications are only detected by mammography. Despite the nominally lower spatial resolution of digital mammography compared to filmscreen mammography, it has been shown that digital mammography screening improves the detection of ductal carcinoma in situ (DCIS) associated with microcalcifications [3-7]. Whereas the detection of microcalcifications on mammography is usually straightforward and may be assisted by employing highly sensitive systems for computer-aided diagnosis (CAD), distinguishing between benign and malignant microcalcifications may be very difficult and, in some situations, impossible without obtaining a biopsy for histological workup [8]. Of microcalcification cases sent to biopsy, usually only $30-50 \%$ of cases represent cancer [9]. Several criteria such as number of individual calcifications in a cluster, spatial distribution, morphology of individual calcifications, and change over time can help in estimating the probability of malignancy for a given microcalcification cluster. In film-screen mammography, air-gap magnification views have traditionally been used to improve the characterization of microcalcifications by better visualizing the morphology of the individual calcifications as well as by showing additional smaller calcifications [10-14].

According to Fischer et al., air-gap magnification views may no longer be necessary in digital mammography and can be replaced by digitally zooming the images [15].

However, their initial study was limited by a small number of cases and the fact that images were read on hard-copy, which does not allow one to exploit the full potential of digital images through interactive manipulation on a reading workstation. The purpose of our study therefore was to test whether additional air-gap magnification views may improve the characterization of microcalcifications in digital mammography using soft-copy reading and a larger number of cases.

\section{Materials and Method}

The institutional ethics committee approved this retrospective study.

The inclusion criteria of the study were defined as follows:

- Complete diagnostic workup in our university hospital

- Digital standard mammography (MG) and digital magnification views in the same plane and on the same system (GE Senographe 2000 D)

- Microcalcifications as dominant suspicious findings

- Magnification views within three months of MG

\section{Study Population}

From January 2000 through December 2007, 42,147 patients underwent mammography at our department for the workup of breast symptoms, follow-up after breast cancer, or early detection of breast cancer.

A total of 14,914 of these patients had a digital mammography. 741 patients in whom two-view digital mammograms demonstrated suspicious microcalcifications underwent additional digital magnification views no more than three months after the initial examination and on the same digital mammography machine and in the same plane as the initial mammography.

35 of these 741 cases were diagnosed with breast cancer (in situ or invasive) and fulfilled the inclusion criteria for our study (complete diagnostic workup including biopsy as well as final surgery performed at our hospital). To create a realistic sample covering the full spectrum of abnormalities, these 35 malignant cases were supplemented by 65 benign cases, which were randomly selected from the original dataset of 741 cases with a valid combination of digital mammography and digital magnification views. Roughly half of the benign cases went to biopsy after the magnification and were confirmed to be benign by histology ( $\mathrm{n}=33 ; 25$ vacuum-assisted biopsies, 8 open surgical biopsies). The other half of the benign cases, which after full assessment did not go to biopsy, were confirmed to be benign by a follow-up of at least 24 months $(n=32)$.

The malignant cases were categorized by the World Health Organization (WHO) classification of breast cancers. Based on the classification published by Elston and Ellis, tumors were graded as well (grade 1), moderately (grade 2), or poorly (grade 3 ) differentiated [16].

\section{Image Acquisition}

All mammographies were acquired using an amorphous siliconebased full-field digital system with a $19 \times 24 \mathrm{~cm}$ detector and $100 \mu \mathrm{m}$ pixel size (Senographe 2000 D, GE Healthcare, Chalfont St. Giles, UK).

The magnification views were obtained with a magnification factor of 1.75 with a standard round spot compression paddle with a diameter of $7 \mathrm{~cm}$. The resulting effective pixel size of the magnification views was $0.057 \mu \mathrm{m}$.

\section{Reader Study}

All images were analyzed using a dedicated digital mammography workstation (MammaReport, Siemens Medical Solutions, Erlangen, Germany) with two 5 megapixel thin film transistor monitors (TFT monitors) and with all viewing features including windowing and electronic zoom available to the readers.

Six radiologists specialized in breast imaging with an average experience in digital mammography of 8.6 years (SD: 6.2 years; range: $1.5-19$ years) participated in the reader study. The cases were collected and prepared by an additional experienced breast radiologist (U. B.). All six readers independently evaluated all 100 cases. Benign and malignant cases were read in random order. All 
images were anonymized prior to the reading, and readers were blinded to patient age, clinical history, and histopathological outcome. During the reader study, only the single contact mammography view corresponding to the plane of the magnification view and no prior films were available to the readers.

If more than one microcalcification area was present in the image, the reader was asked to base the assessment on the most suspicious microcalcification cluster in the image.

All readers first rated the digital contact mammography alone (MG) and then in combination with the digital magnification view (MG+MAG) using a modified 7-point BI-RADS ${ }^{\circledR}$ scale $(1,2$, $3,4 \mathrm{a}, 4 \mathrm{~b}, 4 \mathrm{c}, 5)$ as well as a probability of malignancy scale from $0 \%$ to $100 \%$ [17].

In addition, they were asked to assess the presence of additional subtle microcalcifications on the magnification views on a threepoint scale (none, slightly more without diagnostic relevance, and considerably more with diagnostic relevance) and to compare the subjective visibility of the microcalcifications (MG much better with diagnostic relevance, MG better without diagnostic relevance, no difference, MAG better without diagnostic relevance, MAG much better with diagnostic relevance).

\section{Statistical Analysis}

A receiver operating characteristic ( $R O C)$ analysis was performed using the LABMRMC program provided by the University of Chicago [18].

The area under the curve (AUC) was calculated for each reader individually and for all readers combined using the seven-point modified BI-RADS scale and the probability of malignancy with histology or two-year follow-up results as the reference standard. The sensitivity and specificity were calculated using a four-fold table. A threshold of a ranking BI-RADS 3 and BI-RADS 4a was used for the BI-RADS scale. This statistical analysis was performed using Microsoft Excel 2007 for Windows.

Power calculation estimated a minimum of six readers for the 100 cases to reach significance [19].

\section{Results}

$\nabla$

The mean age of all study patients was 57.3 years (SD, 8.9 years) with a range of 37 to 76 years.

The patients with malignant lesions had a mean age of 58.37 years (SD, 9.27years; range, 40 - 76 years). The subjects with histologically verified benign lesions had a mean age of 58.7 years ( $\mathrm{SD}, 9.3$ years; range, $42-76$ years); the mean age of patients with benign lesions confirmed by follow-up mammographic examinations was 55.3 years (SD 7.9, years; range, $37-72$ years).

There were 12 invasive carcinomas and 23 DCIS.

The histology of the malignant lesions was as follows: 8 invasive ductal carcinomas (3 of grade 2 and 2 of grade 1, 3 not further specified), 1 invasive mucinous carcinoma (grade 2), 1 invasive lobular carcinoma (grade 1), and 2 invasive carcinomas not otherwise specified (NOS).

The preinvasive lesions included 11 high-grade, 6 intermediategrade, and 6 low-grade DCIS.

The histology of the benign lesions was nodular fibrosis in 11 cases, fibrocystic mastopathy in 16 cases, one radial scar, one dysplastic hyaline scar, papilloma in 3 cases, and fatty tissue in one case.

The distribution of mammographic breast density categories (ACR) is presented in $\bullet$ Table 1.
Table 1 Distribution of breast density categories.

Tab. 1 Verteilung der Brustdichte.

\begin{tabular}{|lllll|}
\hline & ACR1 [\%] & ACR2 [\%] & ACR3 [\%] & ACR4 [\%] \\
\hline benign & 1.53 & 36.92 & 49.23 & 2.85 \\
\hline malignant & 1.0 & 51.42 & 45.23 & 2.85 \\
\hline all & 1.1 & 42 & 48 & 9 \\
\hline
\end{tabular}

\section{Visibility of microcalcifications}

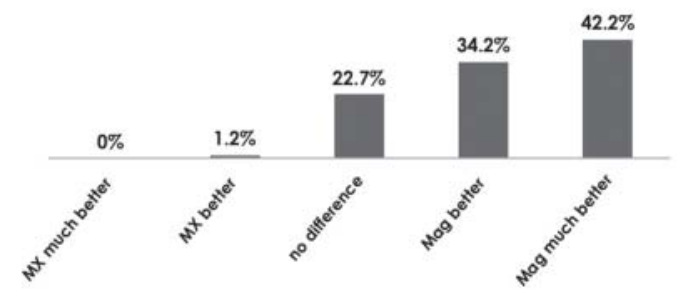

Fig. 1 Columns demonstrating the visibility of microcalcifications in the magnification views compared to the zoomed images ("much better" is defined as diagnostically relevant, "better" does not reach diagnostic relevance). Summation does not exactly reach $100 \%$ due to rounding.

Abb. 1 Das Säulendiagramm stellt die Sichtbarkeit der Mikroverkalkungen in den Vergrößerungsaufnahmen im Vergleich zu den gezoomten Aufnahmen dar. „Much better“ ist als diagnostisch relevant definiert, „, better" ist nicht diagnostich relevant. In der Summe werden aufgrund von Rundung nicht exact $100 \%$ erreicht.

There was no significant difference in the distribution of ACR breast density categories between patients with benign breast lesions and those with breast malignancy ( $\mathrm{p}=0.262)$.

All six readers taken together judged the visibility of the microcalcifications in the magnification views to be superior (with and without diagnostic relevance) to the zoomed images in $75 \%$ of cases (see $\bullet$ Fig. 1). Furthermore, additional microcalcifications were detected on the magnification views in more than two thirds of cases ( $\bullet$ Fig. 2 ).

Regarding the modified BI-RADS scale results of all six readers, the AUC was $0.6643(\mathrm{SD}=0.0518)$ for $\mathrm{MG}$ and 0.8127 for MG + MAG ( $S D=0.0416)$ with a $95 \%$ confidence interval for the population mean difference of -0.2681 to -0.0285 . Individually, each of the six observers showed a higher diagnostic accuracy (AUC) for the combination MG + MAG than MG, with the improvement being statistically significant in four of the six readers (see $\bullet$ Table 2, $\bullet$ Fig. 3 ) and a tendency in favor of the magnification views in one reader.

Regarding the modified probability of malignancy scale, the AUC was $0.6916(\mathrm{SD}=0.0513)$ for $\mathrm{MG}$ and $0.7885(\mathrm{SD}=0.0473)$ for $\mathrm{MG}+\mathrm{MAG}$ with a $95 \%$ confidence interval for the population mean difference of -0.1904 to -0.0033 for all six observers combined. Five of the six readers revealed a higher diagnostic accuracy (AUC) for MG + MAG than MG, with the improvement being statistically significant in three readers (see $\odot$ Table 2, $\odot$ Fig. 4).

Analyzing the influence of the experience of the readers, the time of experience in mammography did not influence the results, as there have been "significant" and "not significant" results in readers with comparable times of experience (see $\bullet$ Table 2 ). 
Table 2 AUC results of the six readers (significant differences are indicated by underlined bold italics).

Tab. 2 AUC-Ergebnisse der sechs Auswerter (signifikante Ergebnisse sind unterstrichen, kursiv und fett hervorgehoben).

\begin{tabular}{|c|c|c|c|c|c|c|c|}
\hline \multirow[b]{2}{*}{ reader } & \multirow[b]{2}{*}{$\begin{array}{l}\text { experience } \\
\text { (years) }\end{array}$} & \multicolumn{3}{|l|}{ BI-RADS } & \multicolumn{3}{|c|}{ probability of malignancy } \\
\hline & & Mx & Mx + Mag & $95 \%$ confidence interval & Mx & $M x+M a g$ & $95 \%$ confidence interval \\
\hline 1 & 8 & 0.6641 & 0.6742 & $-0.0788,0.0586$ & 0.6404 & 0.6235 & $-0.0666,0.1004$ \\
\hline 2 & 5 & 0.7688 & 0.8370 & $-0.1400,0.0036$ & 0.8076 & 0.8551 & $-0.1044,0.0096$ \\
\hline 3 & 1.5 & 0.6515 & 0.8564 & $-0.3149,-0.0950$ & 0.6410 & 0.8175 & $-0.2530,-0.1000$ \\
\hline 4 & 4 & 0.6890 & 0.8223 & $-0.2366,-0.0300$ & 0.7232 & 0.7743 & $-0.1146,0.0124$ \\
\hline 5 & 19 & 0.5652 & 0.8981 & $-0.4409,-2250$ & 0.6541 & 0.8663 & $-0.3030,-0.1215$ \\
\hline 6 & 8 & 0.6473 & 0.7879 & $-0.2400,-0.0421$ & 0.6836 & 0.7943 & $-0.1972,-0.0241$ \\
\hline all & 8.6 & 0.6643 & 0.8127 & $-0.2681,-0.0285$ & 0.6916 & 0.7885 & $-0.1904,-0.0033$ \\
\hline
\end{tabular}

Table showing the overall AUC values as well as the results for every individual reader regarding a modified BI-RADS scale as well as a probability of malignancy scale ranging from $0-100 \%$ chance of malignancy. In the second row every reader's experience in years of reading digital mammography is indicated.

Die Tabelle zeigt die AUC-Kurven für alle Auswerter zusammen und für jeden einzelnen Auswerter für eine modifizierte BI-RADS-Skala und für die Malignitätswahrscheinlichkeit in einer Skala von 0 - 100\%. Die Erfahrung der einzelnen Auswerter in der Mammografie in Jahren ist in der zweiten Spalte dargestellt.

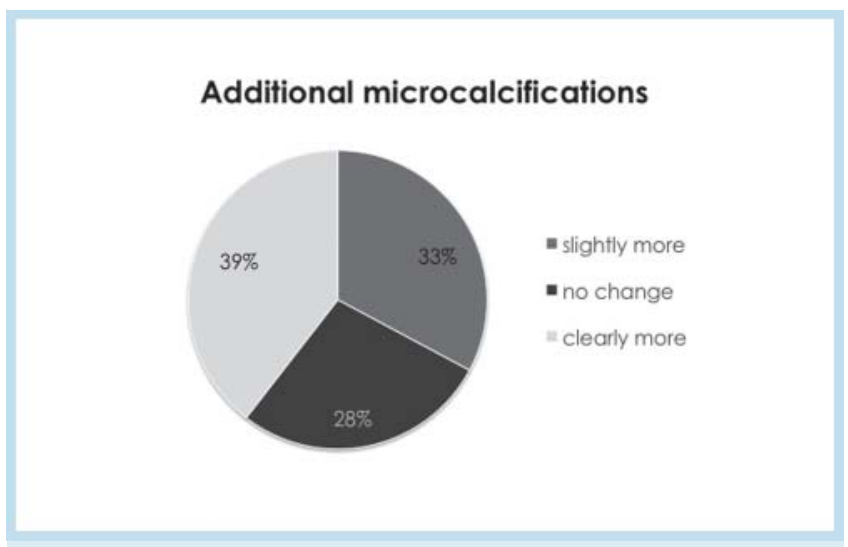

Fig. 2 Percentage of additional calcifications detected by magnification view.

Abb.2 Prozentualer Anteil zusätzlicher, durch die Vergrößerungsaufnahme detektierter Verkalkungen.

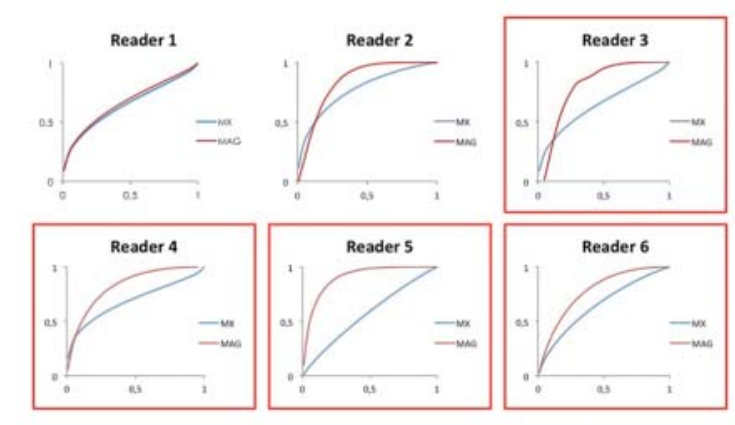

Fig. 3 AUC curves for the BI-RADS scale results of the 6 readers. Significant differences are indicated by framing.

Abb.3 AUC-Kurve der Ergebnisse der BI-RADS-Skala der sechs Reader. Signifikante Unterschiede sind durch einen Rahmen gekennzeichnet.

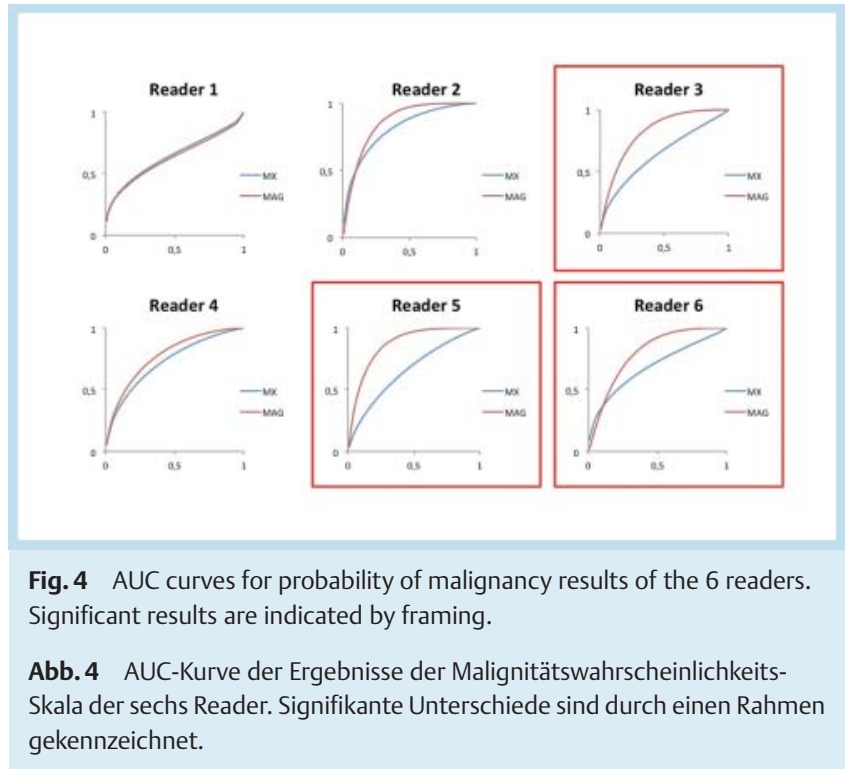

If the observers are divided into three experienced observes and three less experienced observers, there are two "significant" results and one "not significant" result regarding BI-RADS scores in each group.

The distribution of sensitivity, specificity, positive predictive value (PPV), and negative predictive value (NPV) for the cut-offs of BI-RADS 3 and BI-RADS 4a is presented in $\bullet$ Table 3.

There was an improvement of sensitivity independently of the breast density from $69 \%$ in MG to $73.8 \%$ in Mag in ACR 1 and 2 dense breast as well as from $72.2 \%$ to $77.8 \%$ in ACR 3 or 4 dense breasts.

\section{Discussion}

\section{$\nabla$}

Our data clearly confirm that digital air-gap magnification views improve the visibility of microcalcifications, in terms of both number of calcifications and morphology of the individual calcifications. The physical basis for this is mainly the higher spatial resolution of the magnification views. However, other factors such as improved local compression due to the smaller paddle 


\begin{tabular}{|c|c|c|c|c|c|c|}
\hline reader & 1 & 2 & 3 & 4 & 5 & 6 \\
\hline \multicolumn{7}{|c|}{ cutoff $>=$ BI-RADS 3} \\
\hline sensitivity $\mathrm{Mx}$ & $100.0 \%$ & $94.3 \%$ & $65.7 \%$ & $71.4 \%$ & $88.6 \%$ & $71.4 \%$ \\
\hline specificity Mx & $1.5 \%$ & $30.8 \%$ & $49.2 \%$ & $50.8 \%$ & $23.1 \%$ & $50.8 \%$ \\
\hline PPV & 0.354 & 0.423 & 0.411 & 0.439 & 0.383 & 0.439 \\
\hline NPV & 1.000 & 0.909 & 0.727 & 0.767 & 0.789 & 0.767 \\
\hline sensitivity Mag & $100.0 \%$ & $100.0 \%$ & $97.1 \%$ & $94.3 \%$ & $100.0 \%$ & $97.1 \%$ \\
\hline specificity Mag & $0.0 \%$ & $26.2 \%$ & $60.0 \%$ & $46.2 \%$ & $32.3 \%$ & $35.4 \%$ \\
\hline PPV & 0.350 & 0.422 & 0.567 & 0.485 & 0.443 & 0.447 \\
\hline NPV & 0.000 & 0.000 & 0.000 & 0.000 & 0.000 & 0.000 \\
\hline \multicolumn{7}{|c|}{ cutoff $>=$ BI-RADS $4 a$} \\
\hline sensitivity $\mathrm{Mx}$ & $68.6 \%$ & $71.4 \%$ & $54.3 \%$ & $51.4 \%$ & $51.4 \%$ & $57.1 \%$ \\
\hline specificity Mx & $40.0 \%$ & $60.0 \%$ & $69.2 \%$ & $80.0 \%$ & $44.6 \%$ & $53.8 \%$ \\
\hline PPV & 0.381 & 0.490 & 0.487 & 0.581 & 0.333 & 0.400 \\
\hline NPV & 0.703 & 0.796 & 0.738 & 0.754 & 0.630 & 0.700 \\
\hline sensitivity Mag & $80.0 \%$ & $100.0 \%$ & $74.3 \%$ & $71.4 \%$ & $97.1 \%$ & $85.7 \%$ \\
\hline specificity Mag & $29.2 \%$ & $47.7 \%$ & $73.8 \%$ & $76.9 \%$ & $61.5 \%$ & $53.8 \%$ \\
\hline PPV & 0.378 & 0.507 & 0.605 & 0.625 & 0.576 & 0.500 \\
\hline NPV & 0.731 & 1.000 & 0.842 & 0.833 & 0.976 & 0.875 \\
\hline
\end{tabular}

Table 3 Sensitivity, specificity, PPV and NPV for different cutoffs regarding the BI-RADS scale.

Tab. 3 Sensitivität, Spezifität, PPV und NPV für unterschiedliche Grenzwerte der BI-RADS-Einteilung.
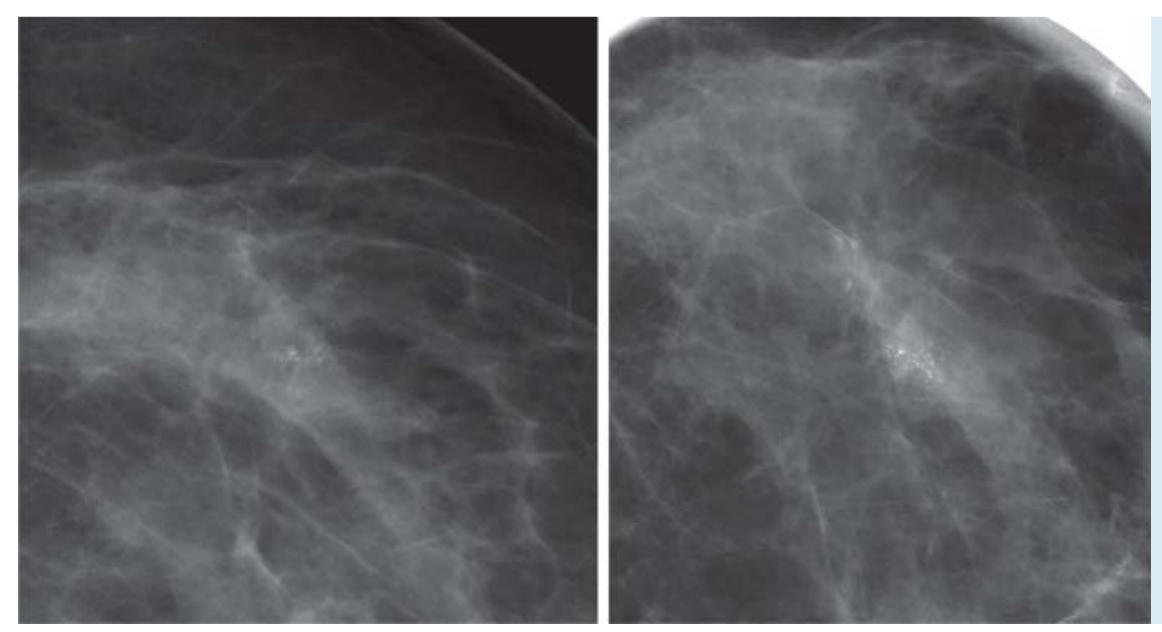

Fig. 5 Example of an invasive ductal carcinoma showing better delineation of the microcalcifications and more prominent density in the magnification view on the right compared to the normal mammography view on the left.

Abb.5 Beispiel eines invasiv-duktalen Mammakarzinoms. In der Vergrößerungsaufnahme zeigen sich im Vergleich zur normalen Mammografie die Mikroverkalkungen deutlicher abgegrenzt und die Verdichtung kommt deutlicher zur Darstellung.

may also play a role. What is more important, however, is how much this improved visibility of microcalcifications in magnification views will turn out to be beneficial to patients ( see $\bullet$ Fig. 5). Patients would benefit, for example, if a more confident characterization of microcalcifications could spare patients unnecessary biopsies or help for instance to avoid delays in cancer diagnosis. In 2002, Fischer et al. did not find a significant benefit of additional magnification views regarding the overall diagnostic accuracy of digital mammography. Four readers (two with more than 15 years, one with one and one with three years experience) evaluated 55 patients with 57 microcalcification-associated lesions (21 malignant, 36 benign) using the BI-RADS scale. They found overall better results for the magnification views, but no statistically significant differences and therefore concluded that most problems can be solved with digital zooming and that omission of additional magnification views has the potential to improve workflow, to lower radiation exposure, and to reduce the recall rate in a digital mammography-based screening program. [15] However, the major limitation of this study is the use of hard copy reading alone.

Recently, Kim et al. found in an analysis of 120 clusters with three readers (1, 2 and 10 years of experience, 6.3 years average) that magnification mammograms were superior to contact mammography when using a zoom factor of 1.8 [20]. Another recent study published by Kim et al. compared a magnification factor of 1.8 and a zoom factor of 2.0 for the assessment of microcalcifications. They read 185 clusters with three radiologists $(4,5$ and 12 years experience, 7 years average). As a major result, the authors did not find any significant differences between zooming and geometrical magnification regarding sensitivity, specificity, and AUC analysis of a probability of malignancy score that was comparable to a modified BI-RADS scale [21].

The most recent study was published by Moraux-Wallyn et al., who found geometrical magnification to be better than electronic zooming in terms of sensitivity, specificity, PPV, and NPV, but the difference was not statistically significant. This study included 88 clusters of microcalcifications analyzed by two readers [22]. These results are inline with ours showing an improvement of sensitivity for all readers in magnification views.

In our study, we used the maximum geometrical magnification of 1.8 and a comparable zooming factor of 2.0 to identify a possible benefit of true magnification views using soft-copy reading or to show if there is an influence due to the possibility to use digital zooming.

With these parameters, the diagnostic performance of geometrical magnification was found to be superior to zooming. Furthermore, these results were statistically significant. $A_{z}$ values of 
MAG were at a higher level in all readers regarding BIRADS. Ours is the first study showing a statistically significant difference for all readers combined as well as for four individual readers with experience of 1.5, 4, 8 and 19 years regarding a BI-RADS scale. A possible explanation for the lack of statistical significance in earlier studies is the smaller number of readers, resulting in a lower statistical power for the ROC analysis. For two of the readers in our study, one with 8 years of experience and one with 5 years of experience, the difference was not statistically significant as well, but there was a tendency in favor of true magnification in the last one.

The statistical power analysis for our data collection of 100 cases estimated a minimum number of readers necessary to reach statistical significance to be 6 .

None of the previous studies reached such a combined number of cases or readers.

Another major benefit of our study was the huge range of experience among the readers ( 1.5 years to 19 years) resulting in significant and not significant outcomes in experienced and less experienced examiners.

Regarding the distribution of reader experience in previously published studies, they contain more inexperienced readers with less than 5 years of experience than we included in our study.

Kimme-Smith et al. [23] could show that experience in interpreting mammography positively influences the performance in judging microcalcifications in digitized enhanced and truly magnified images in favor of the more experienced readers. This could lead to the assumption that the experience time influenced the results in our study as well.

If only readers with minimal experience would benefit from an additional magnification view and the resulting additional radiation dose would only equalize a lack of experience, it would be unacceptable in a diagnostic and screening mammography setting. Especially in the screening of potentially healthy woman, the dose has to be as low as possible to avoid any harm for the patient particularly if digital mammography offers the opportunity to reduce the radiation dose [24, 25].

Nevertheless, a lack of experience was not the explanation for the difference in significance, as the "not significant" results were achieved by quite experienced readers with 5 and 8 years of experience. Even if we divide our readers into two groups, experienced (11.7 years average) and less experienced (3.5 years average), two of three results were significant in each group.

There is a major difference between our study and earlier reports. We included histologically proven benign and malignant lesions as well as benign cases verified by follow-up mammograms. Thus, we covered the whole spectrum of microcalcifications that may be encountered in the clinical setting. The only other studies assessing the same range of microcalcification types included a much smaller number of cases than our study $[15,20]$. All other studies only assessed microcalcifications classified as suspicious enough to warrant biopsy.

But how did magnification views improve diagnostic performance in our study?

The resulting decrease in pixel size improved the delineation of the shape and contour of calcifications. This effect has been shown by Ruschin et al. [26]. More very tiny calcifications were visible, which has an impact on the assessment of the extent of the affected region and therefore allows individual surgery planning to achieve free margins resulting in the fewest possible surgeries. [26]

Another limitation on making things visible is the capability of the human eye.
It is known from several studies that calcifications as small as $130 \mu \mathrm{m}$ are visible to the human eye $[27,28]$.

With the decrease in pixel size in magnifications and the less attenuated dose (magnification views are obtained without a grid), there is much more information/photons per pixel in more pixels [29]. This results in a higher effective spatial resolution, which may improve visibility by sharpening object delineation and facilitating the differentiation of calcifications from overlying structures.

Spot views with focal compression reduce overlying structures. With the use of a small spot compression plate and magnification, we reduced the overlying tissue even more than with magnification views alone. It has been shown that overlying tissue/ structures significantly reduce the detection rate of microcalcifications [29]. The magnification and reduction of overlying tissue by compression may jointly have contributed to the better diagnostic performance in our study.

\section{Limitations}

\section{$\nabla$}

One limitation of this study is that we only tested one detector. Hence, our results may not be transferable to other digital mammography systems using different pixel sizes, focal spot sizes, image noise, and magnification factors.

Another limitation of the study is the fact that the readers knew whether they were judging a normal mammography or a magnification.

Finally, magnification views are obtained with a higher dose than normal mammograms. Hence, it is not clear if the higher radiation dose contributed to the improved visibility.

\section{Conclusion}

Even in digital mammography with the option of using electronic magnification (zoom) at the viewing workstation, true geometric (air-gap) magnification views remain important for visibility and correct classification and the assessment of the extent of microcalcifications.

\footnotetext{
Affiliations

1 Clinic of Radiology, Campus Virchow-Klinikum, Charité - Universitätsmedizin, Berlin

2 Institute of diagnostic and interventional Radiology, DRK-Kliniken BerlinMitte, Berlin

3 Department of Medical Imaging, St. Joseph-Stift, Bremen

4 Neuroimaging for Research, Berlin

5 Reference-Centre of Mammography-Screening, Berlin

6 Department of Radiology, Campus Charité Mitte, Charité - Universitätsmedizin, Berlin

7 Breast Center, Department of Gynecology, Campus Charité Mitte, Charité - Universitätsmedizin, Berlin
}

\section{Acknowledgments \\ $\nabla$}

„This manuscript is dedicated to Professor Bernd Hamm for his 60th birthday.“

Without his support and continuous affords in providing a high end equipped Institution research would not be possible.

We are thankful to Professor Marc Dewey for discussions about this paper. 
The authors thank Bettina Herwig for editorial support in preparing the manuscript.

\section{References}

1 Weigel S, Decker T, Korsching E et al. Calcifications in digital mammographic screening: improvement of early detection of invasive breast cancers? Radiology 2010; 255: 738 - 745

2 Moon WK, Im JG, Koh YH et al. US of mammographically detected clustered microcalcifications. Radiology 2000; 217: 849-854

3 Skaane P, Skjennald A. Screen-film mammography versus full-field digital mammography with soft-copy reading: randomized trial in a population-based screening program-the Oslo II Study. Radiology 2004: 232: $197-204$

4 Skaane P, Hofvind S, Skjennald A. Randomized trial of screen-film versus full-field digital mammography with soft-copy reading in population-based screening program: follow-up and final results of Oslo II study. Radiology 2007; 244: $708-717$

5 Skaane P, Balleyguier C, Diekmann F et al. Breast lesion detection and classification: comparison of screen-film mammography and full-field digital mammography with soft-copy reading-observer performance study. Radiology 2005; 237: 37-44

6 Pisano ED, Gatsonis C, Hendrick E et al. Diagnostic performance of digital versus film mammography for breast-cancer screening. $\mathrm{N}$ Engl $\mathrm{J}$ Med 2005; 353: 1773-1783

7 Obenauer S, Hermann KP, Schorn C et al. Digitale Vollfeldmammographie: Phantomstudie zur Detektion von Mikrokalk. [Full-field digital mammography: a phantom study for detection of microcalcification]. Fortschr Röntgenstr 2000; 172: 646-650

8 Rominger $M$, Wisgickl C, Timmesfeld $N$. Breast microcalcifications as type descriptors to stratify risk of malignancy: a systematic review and meta-analysis of 10665 cases with special focus on round/punctate microcalcifications. Fortschr Röntgenstr 2012; 184: 1144-1152

9 Kettritz U, Morack G, Decker T. Stereotactic vacuum-assisted breast biopsies in 500 women with microcalcifications: radiological and pathological correlations. Eur J Radiol 2005; 55: 270 - 276

10 Sickles EA. Mammographic detectability of breast microcalcifications. Am J Roentgenol Am J Roentgenol 1982; 139: 913-918

11 Sickles EA. Further experience with microfocal spot magnification mammography in the assessment of clustered breast microcalcifications. Radiology 1980; 137: 9-14

12 Oestmann JW, Kopans DB, Linetsky L et al. Comparison of two screenfilm combinations in contact and magnification mammography: detectability of microcalcifications. Radiology 1988; 168: 657-659

13 Law J. Breast dose from magnification films in mammography. $\mathrm{Br} J$ Radiol 2005; 78: 816-820

14 Diekmann F, Diekmann S, Bick $U$ et al. Vergleich der Visualisierung von Mikroverkalkungen durch Vergrosserungsaufnahmen in digitaler Vollfeldmammographie und konventioneller Mammographie. [Comparing the visualization of microcalcifications with direct magnification in digital full-field mammography vs. film-screen mammography] Fortschr Röntgenstr 2002; 174: 297-300

15 Fischer U, Baum F, Obenauer S et al. Digitale Vollfeldmammographie: Vergleich zwischen radiographischer Direktvergrösserung und digitalem Monitorzooming. [Digital full field mammography: comparison between radiographic direct magnification and digital monitor zooming]. Radiologe 2002; 42: 261 -264

16 Elston CW, Ellis IO. Pathological prognostic factors in breast cancer. I. The value of histological grade in breast cancer: experience from a large study with long-term follow-up. Histopathology 1991; 19: $403-410$

17 Carl JDO. Radiology ACo, Committee ACoRB-R. . Illustrated Breast Imaging Reporting and Data System (Illustrated BI-RADS). American College of Radiology; 1998

18 Metz CE. ROC methodology in radiologic imaging. Invest Radiol 1986; 21: $720-733$

19 Schueler S, Schuetz GM, Hamm B et al. Lesen und Interpretieren von Metaanalysen diagnostischer Genauigkeitsstudien. [Reading and interpreting meta-analyses of diagnostic accuracy studies]. Fortschr Röntgenstr 2011; 183: 799-803

$20 \mathrm{Kim}$ MJ, Kim EK, Kwak JY et al. Characterization of microcalcification: can digital monitor zooming replace magnification mammography in full-field digital mammography? Eur Radiol 2009; 19: 310 - 317

21 Kim MJ, YoukJH, Kang DR et al. Zooming method $(\times 2.0)$ of digital mammography vs digital magnification view $(\times 1.8)$ in full-field digital mammography for the diagnosis of microcalcifications. $\mathrm{Br} \mathrm{J}$ Radiol 2010; 83: 486-492

22 Moraux-Wallyn M, Chaveron C, Bachelle F et al. Comparison between electronic zoom and geometric magnification of clusters of microcalcifications on digital mammography. J Radiol 2010; 91: 879-883

23 Kimme-Smith C, Gold RH, Bassett LW et al. Diagnosis of breast calcifications: comparison of contact, magnified, and television-enhanced images. Am J Roentgenol Am J Roentgenol 1989; 153: 963-967

24 European Society of R. White paper on radiation protection by the European Society of Radiology. Insights into imaging; 2011; 2: 357-362

25 Weigel S, Girnus R, Czwoydzinski J et al. Digital mammography screening: average glandular dose and first performance parameters. Fortschr Röntgenstr 2007; 179: 892-895

26 Ruschin M, Hemdal B, Andersson I et al. Threshold pixel size for shape determination of microcalcifications in digital mammography: a pilot study. Radiat Prot Dosimetry 2005; 114: 415-423

27 Karssemeijer N, Bluekens AM, Beijerinck D et al. Breast cancer screening results 5 years after introduction of digital mammography in a population-based screening program. Radiology 2009; 253: 353-358

28 Cowen AR, Launders JH, Jadav M et al. Visibility of microcalcifications in computed and screen-film mammography. Phys Med Biol 1997; 42: $1533-1548$

29 Lai C-J, Shaw CC, Whitman GJ et al. Visibility of simulated microcalcifications-a hardcopy-based comparison of three mammographic systems. Med Phys 2005; 32: 182-194 